\title{
Idiopathic Thrombocytopenic Purpura with Intracranial Haemorrhage and Menorrhagia
}

\author{
SDAS $^{\mathrm{a}}, \mathrm{BR}^{\mathrm{B}} \mathrm{CHOWDHURY}{ }^{\mathrm{b}}, \mathrm{RBEGUM}^{\mathrm{c}}$
}

\begin{abstract}
Summary:
$A$ rare and life threatening complication of idiopathic thrombocytopenic purpura is intracranial hemorrhage ( ICH) and is the leading reported cause of death. The other important manifestation of ITP is menorrhagia. There are a variety of different causes of menorrhagia and gynecological evaluation is essential to tailor management to the individual patient to prevent unnecessary invasive procedure which may have limited effect. A 25 years old female para-2+0 presented with menorrhagia,severe excruciating headache,easy bruising, ecchymosis and petechialhemorrhage. After all
\end{abstract}

\section{Introduction:}

Although relatively rare, intracranial hemorrhage (ICH) is the most serious complication of idiopathic thrombocytopenicpurpura (ITP) and is the leading reported cause of death ${ }^{1,2,3}$. ICH was verified by computed tomography $(\mathrm{CT})$ scan.

Menorrhagia is a gynecological condition which adversely affects quality of life for many women. Acute Menorrhagia can be defined as excessive menstrual or intermenstrual bleeding occurs in a women of child bearing age requires emergency treatment excluding pregnancy, postpartum hemorrhage, trauma and malignancy ${ }^{4,5}$. There are a variety of different causes of menorrhagia, and gynecological evaluation is essential.To tailor management to the individual patient to prevent unnecessary invasive procedures this may have limited effect. Inherited bleeding disorders have been linked to a significant prevalence of menorrhagia with Vonwillebrand disease, platelet function disorder. ${ }^{6,7}$ The incidence and

a. Dr. Suchanda Das, Junior Consultant (Gynae), Department of Obstetrics and Gynaecology, Chittagong Medical College.

b. Dr. Bidhan Roy Chowdhury, Associate Professor (Paediatrics), BBMH, University of Science and Technology Chittagong

c. Prof. Rokeya Begum, Department of Obstetrics and Gynaecology, Chittagong Medical College Hospital.

Address of Correspondence: Dr. Suchanda Das, Junior Consultant (Gynae), Department of Obstetrics and Gynaecology, Chittagong Medical College.

Received: 1 March 2016

Accepted: 13 March 2017 investigation clinical evaluation it was diagnosed as a case of ITP with intracranial hemorrhage and menorrhagia. An intracranial hemorrhage is the most dreaded complication of ITP it is essential toprecede an early diagnosis, prompt and aggressive management and optimizing the management of acute menorrhagia remains of clinical importance due to life threatening nature of the condition.

Keywords: Idiopathic thrombocytopenic purpura, subdural hematoma, menorrhagia, intracranial hemorrhage.

(J Bangladesh Coll Phys Surg 2017; 35: 97-99)

clinical significance of acute menorrhagia in women with underlying disorders of homeostasis, however, are often underestimated.

However, excessive menstrual bleeding is all toooften considered as being due to purely local Causes, with the result that such procedures as dilatation and curettage and even hysterectomy have been performed. The simple procedures of studies a blood smear for blood platelets would have revealed the almost complete lack of these cellular clement and thus have prevented the various gynecological procedures.

\section{Case Report}

A 25 years old female, para $2+0$ presented with menorrhagia for a period of about two months,severe headache and easy bruises, ecchymosis and petechial hemorrhage. Early in the present illness, she had noted purpuricspot on the legs, ecchymosis on the arm, apparently unrelated to trauma. Her menses began to increase in duration and quantity of flow for about two months. She had also severe excruciating headache which is gradually increasing. There was no family history of a hemorrhagic tendency or any other blood dyscrasias. No history of recent infection myalgia's,arthralgia, rash, fever,chills. Photophobia or Systemic lupuserythromatosuswas excluded. She had not been taking any medications that could precipitate ITP. She is a known case of DM \& HTN. After 2 unit of blood transfusion her headache was gradually subsided. Examination revealed acutely ill patient. Who was a febrile with a blood pressure of 140/100 $\mathrm{mm}$ of hg . 


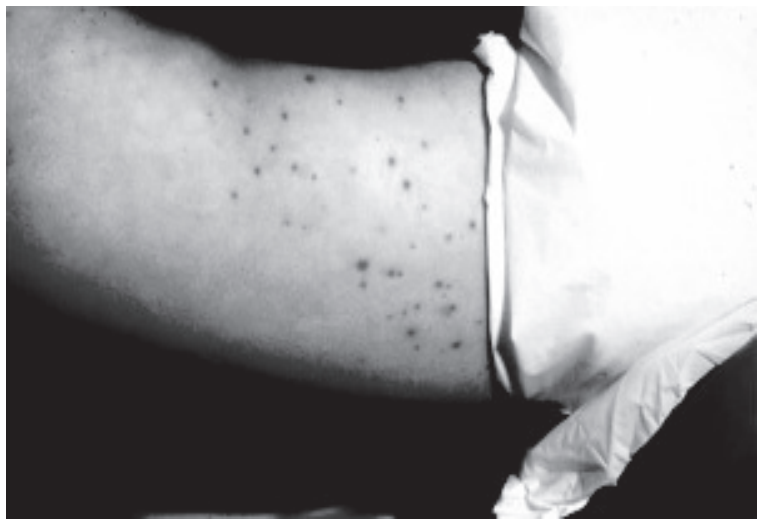

There was purpura, ecchymosis, but no rash. There was subconjuntival hemorrhage. No splenomegaly or lymphadenopathy. Neurological examinationsrevealed normal fundi and no foci of neurologicaldeficits. Laboratory investigations revealed a hemoglobin of 6.7 $\mathrm{gm} / \mathrm{dl}$. White blood count of $9000 / \mathrm{cmm}$, platelet count 20,000/ cumm, PCV-26\%, Differential count of white blood cell no significant change., FBS- $190 \mathrm{mg} / \mathrm{dl}$, $2 \mathrm{hrs}$ after breakfast $-280 \mathrm{mg} / \mathrm{dl}$ CT scan of head revealed subdural hemorrhage over the right cerebral hemisphere with mass effect.

Peripheral blood film shows thrombocytopenia. Prothrombin Time \& APTT was normal.

Bone marrow aspirate showed increased megakaryocytes consistent with peripheral platelet destruction.

The work up for the etiology of her thrombocytopenia including autoimmune and microbiological serology was completely negative. A diagnosis of acute ITP was made.

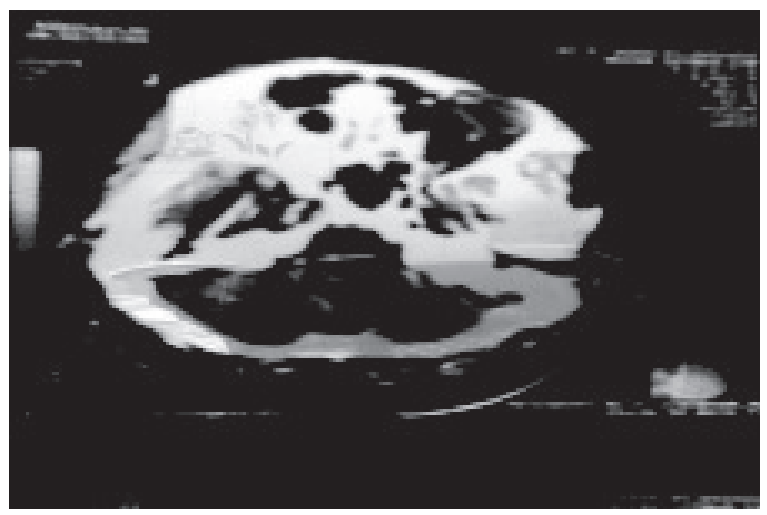

Considering the severity of the case and potential for a fatal outcome, therapy was initiated with 2 units of platelet and 3units of packed red cell transfusion over the first 48 yrs. But platelet countnotimproved but feature of ICH gradually subsided.

Treatment was started with intravenous dexamethasone then switched over to oral oradexon\&phenobarbitone, Insulin \&anti-hypertensive. Oral steroid tapered over next 2 weeks and eventually discontinued \& no further bleedingepisodes occurred. ICH was managed conservatively without surgical intervention. After 2 weeks of treatment $-\mathrm{HB} \%-13.4 \mathrm{gm} / \mathrm{dl}$, platelet count 2,50,000 cm, CT. scan - no abnormality.

\section{Discussion:}

The most serious and life threatening complication of ITP is ICH. ${ }^{1,8,9}$. Fortunately ICH is rare in ITP and probably occurs is less than $1 \%$ of all cases of ITP $2,3,9,10$. The hemorrhages are usually found in the subarachnoid areas, but can occur in intracranial spaces ${ }^{9}$.Inthis case hemorrhage in subdural space, posterior fossa hemorrhages are especially dangerous due to the possibility of rapid cerebellar herniation and brain stem compression. Retinal hemorrhage often occurs at the time of $\mathrm{ICH}^{8}$. In our casepurpura and hemorrhage occur spontaneously both in subdural space \& sub conjunctival hemorrhage.

Acute ITP is mainly a disease of child hood occursin equal frequency in both sexes and chronic ITP occurs most commonly in adult typically under the age of 40 with female to male ratio 3:1 as observed world wide ${ }^{11}$. A Platelet count below $1,00,000 / \mathrm{ml}$ in generally considered to constitute thrombocytopenia. However spontaneous bleeding does not become evident until platelet count falls to 20,000 cumm $^{12}$.

Treatment for acute menorrhagia in patients with underlying thrombocytopenia or a platelet function disorder should include management of the underlying disorder i.e Platelet transfusion which is applicable in my case. In literature review, it was shown that, there was severe menstrual bleeding requiring numerous blood transfusions; hysterectomy was performed on the mistaken assumptions that uterine fibroids were the cause of the bleeding. When vaginal bleeding continued after hysterectomy a hemorrhagic disease was suspected and ITP found. Soproper evaluation should be needed before treatment of menorrhagia. 
Therapy for ICH associated with ITP consist of controlling ICP while also achieving a rapid rise in the platelet count to control bleeding with $1 / \mathrm{v}$ dexamethasone and $20 \%$ manitol can be implement to control cerebral oedema ${ }^{13}$ If the neurological sign aggravate then neurosurgical intervention may be warranted but the decision to operate has to be taken considering the risk and benefit of the individual case. But in the studies patient's intracranial hemorrhage manage conservatively $\&$ there was no residual effect.

\section{Conclusion:}

An intracranial hemorrhage is the most dreaded complication of ITP, it is essential to proceed on early diagnosis, prompt and aggressive management.

Optimizing the management of acute menorrhagia remains of clinical importance due to the life threatening nature of the condition. The wide variety of causes of the condition emphasizes the need to correctly evaluate the underlying causes and tailor management accordingly.

\section{References}

1. Komrower G M, \& Watson, G. H. Prognosis in Idiopathic thrombocytopenic purpura of Childhood. Arch Dis Child 1954, 29:502-506.

2. Woerner, S. J, Abildguard, C. F. French B N, Intracranial hemorrhage in children with Idiopathic thrombocytopenic purpura; Pediatrics 1981, 67: 453-460.
3. Lusher J M, Zuelzer, W.W.Idiopathic thrombocytopenic purpura in childhood; J Pediatr 1966, 68:971-979.

4. Show R W, Brickley MR, Evans L, Edwards MJ; Perception of woman on the impact of menorrhagia on their health winy multi-attribute utility assessment. $\mathrm{Br} \quad \mathrm{J}$ obstetGynaecal 1998:105: 1155-9.

5. Shanker M, Chic, Kadir RA, Review of quality of life; Menorrhagia in women with or without inherited bleeding disorder, Hemophilia 2008: 14:15-20.

6. Lee CA, Women and inherited bleeding disorder; Menstrual issues, SesinHematal 1999:36:21-7.

7. Shankar M, Lee CA, Sabin CA, Eeonomides DI, Kadir RA , Von Willebrand disease in women with menorrhagia; A systematic review. BJOG 2004; 111:734-40.

8. Mueller Eckhardt C, Idiopathic thrombocytopenic purpura, clinical and immunologic consideration, SeminThomsHemost 1977, 3: 125-159.

9. Wintrobe M, Idiopathic thrombocytopenic purpura.In wintrobe, M, (ed) Clinical haematology, $7^{\text {th }}$ edition. Lea \&Febiger, Philadelphia, 1974, p1075.

10. Lusher LM \& Iyer R. Idiopathic thrombocytopenic purpura in children, SeminThombHemost 1977. 3: 175194.

11. Kumar U, Abbas AK, Asher JC, Pathologic basis of disease, $8^{\text {th }}$ ed,Philadelphia: Elsevier; 2010, p666-70.

12. Sirgh T. Text book of Hematology, $2^{\text {nd }}$ ed, New Delhi, Aryar Publication; 2010. P2204.

13. Eraig JEO, McClelland DBL, Watson HG, Blood disease, Incolledye NR, Wather BR, RalstonSH $5^{\text {th }}$ edition. Davidson's Principle and practice of medicine, $21^{\text {st }} \mathrm{ed}$, India, Churchill Livingstone. 2010, p-998-1002 